\title{
Levitation of Cells
}

\author{
Chetana Krishnan \\ B.E-Biomedical engineering ( $2^{\text {nd }}$ year), Sri Sivasubramanya Nadar College of Engineering, \\ Kalavakkam, Chennai, Tamil Nadu, India
}

\begin{abstract}
In the current trend, cancer has become something like cold. Almost in every street, at least three people fight cancer. The traditional method of curing cancer includes chemotherapy and pills. But it is effective only at the early stages of cancer. Till now, no cure has been found in curing cancer completely. The principle behind chemotherapy involves the killing of cancer cells by passing high level radiation such as gamma radiation through the body. Moreover chemo causes post complications such as hair loss, weight loss etc. which makes the person's life miserable. The other problem which currently exists in the surgical area is removal of small stones (of size less than a unit sphere) in sensitive organs like uterus etc. For example, in the case of removal of uterine stones, since the tube is very small to be overloaded, a slight defocus during incision can cause severe complication and lead to the death of the patient.

The size of uterine tube is really small for the incision procedure to take place. If any stone of fibrous type gets formed in the walls of this tube, it becomes really difficult to cut open the tube and remove the stone. Sometimes due to deep tear of the tube, the muscles get damaged and the person may die. So, the important problems that the doctors and the pathologists face nowadays are finding a remedy for cancer and removal of stones from sensitive areas. The solution that we could develop is something common to both the problems and this solution will be useful to cure both the problems. That is some platform which can remove stones with ease and also destroy cancer cells.
\end{abstract}

Keywords — Levitation; Incision; Acoustic; Ultrasonic; Platform.

\section{Introduction}

\subsection{Definition of Problem}

- Frequent death due to inappropriate treatment of cancer.

- Complications during surgery in the removal of stones.

\subsection{Objectives of the Proposed Work}

- To find an alternative efficient way of curing cancer by the method of upliftment of cells.

- To create comfort while removing small fibrous tissues from sensitive areas.

\subsection{Target Beneficiaries}

This method will be extremely useful for those suffering from cancer and those who are carrier of fibrous stones.

\subsection{Proposed Project}

Levitation is the process by which something is uplifted defying the action of gravity. Imagine applying this concept as a solution to the stated problems. The cancer cells can be differentiated from normal cells by using certain specific algorithms and they can be levitated by suitable mechanism. Similarly, they can be used to levitate the uterine or any other stone from the patient's body with ease, which will prevent the digging of tube thus preventing muscle damage. But for that, we must know the right type of levitation that can be used. There are many types of levitation available such as acoustic (using sonic waves), optical (using light rays especially blue light), magnetic (using semiconductors and magnetic field) etc.

In a survey conducted across hospitals and pathology centre such as Lema labs, Lister labs, we came to a conclusion regarding the right type of levitation. It was noted that acoustic levitation using sonic waves was far better than other methods. The following were the reasons:

- Highly efficient about $97 \%$.

- Wave signals were found to be more accurate as compared to other levitating mechanisms.

- The output obtained was linear with the input provided.

- Required least power and supply voltage.

- Can be used in all climatic and external conditions whereas the other methods had restrictions towards operating field.

- Using sonic waves were sensitive as compared to light rays or magnetic field.

\section{Methodology}

The work plan is divided into several steps such as formation of formalin resistant base, implementing suitable algorithm, Creating the acoustic base, circuit design, work plan and materials. 


\subsection{Formation of Formalin Resistant Base}

The human cells have unique property of showing resistance towards the solution called formalin. This method of implementing formalin resistant base will be adopted in the fabrication of cells at the pathology centre by pathologists in the test of bacteria and also in the case of fabrication of cells. The created base will be made magnetic using appropriate magnetic fields and semiconductors (solenoids).

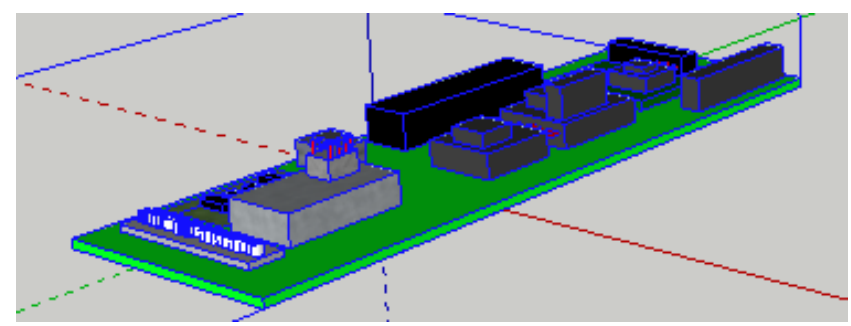

Fig. 1: Formalin resistant base with appropriate magnetic spacing

\subsection{Implementing Suitable Algorithm}

Using MATLAB and other machine learning language, a suitable algorithm to distinguish between abnormal cells and normal cells will be made and will be integrated with the formalin base.

\subsection{Creating the Acoustic Base}

The principle of acoustic tweezers will be enhanced and acoustic base will be created using the methods of levitation. Unlike chemotherapy levitation when exposed to human body is completely harmless as it is only involved around the defected cells as per the algorithm. Finally the integrated device will be created which can levitate cells with appropriate intensity.

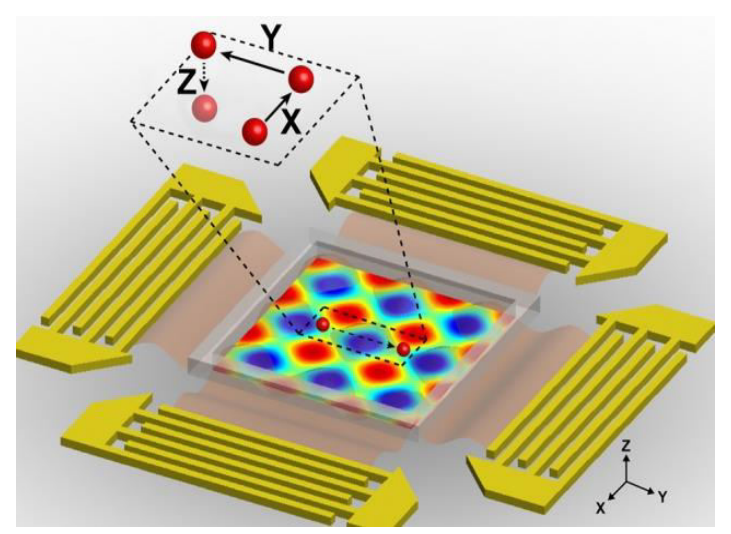

Fig. 2: Acoustic Base

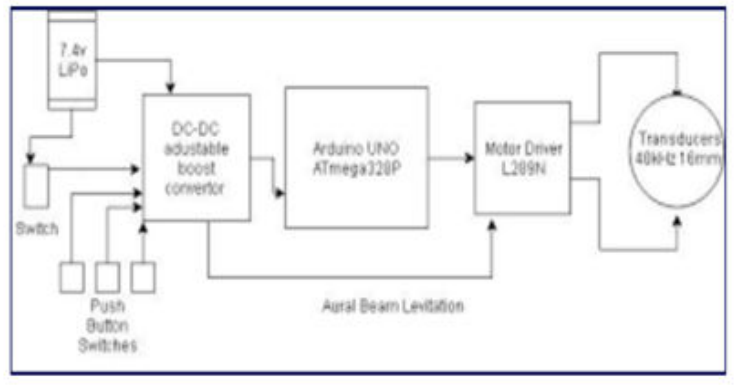

Fig.3: Circuit design

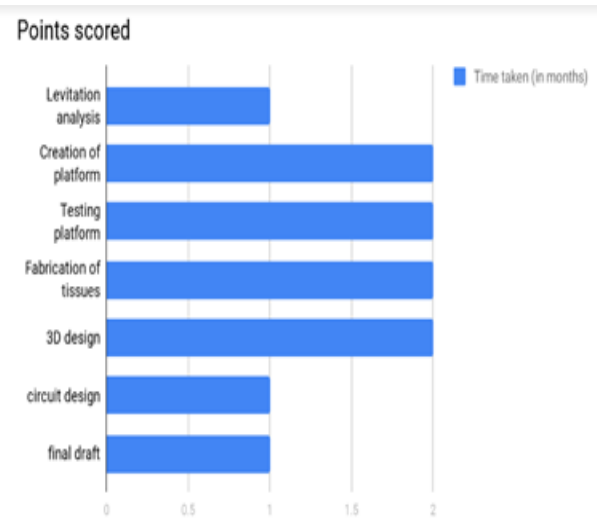

Fig.4: Work plan

\subsection{Materials}

The following figure shows the list of component required for the project along with its cost per unit component.

\begin{tabular}{|c|c|c|}
\hline Material & Qty & $\begin{array}{l}\text { Cost } \\
\text { (in Rs) }\end{array}$ \\
\hline Probes & 2 & 199 \\
\hline Tweezers & 3 & 500 \\
\hline $\begin{array}{l}\text { Optical } \\
\text { reflectors }\end{array}$ & 4 & 500 \\
\hline $\begin{array}{l}\text { Levitating } \\
\text { cups }\end{array}$ & 5 & 99 \\
\hline Magnets & 6 & 66 \\
\hline $\begin{array}{l}\text { Super } \\
\text { conductors }\end{array}$ & 4 & 54 \\
\hline US source & 2 & 900 \\
\hline $\begin{array}{l}\text { Inductive } \\
\text { capacitors }\end{array}$ & 1 & 1200 \\
\hline $\begin{array}{l}\text { Machine build } \\
\text { - ups }\end{array}$ & 1 & 1500 \\
\hline Cells & 1 pack & 15000 \\
\hline Arduino kits & 1 pack & 800 \\
\hline
\end{tabular}

Fig.5: Materials used 


\section{Results}

\subsection{Comparison Between Types of Levitation}

In an experiment conducted, we came to know that acoustic levitation was the best as compared to other types of levitation because it levitated the cells to the maximum extend as compared to other types of levitation.

$$
(\because)
$$$$
\mid
$$

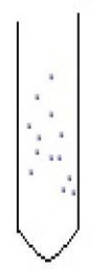

Magnetic
Optical

Acoustic
Fig.6: Types of levitation

\section{Comparison Between Chemo and Levitation}

A study was done to obtain the waveform of cells to a patient who has undergone chemo for cancer. The graph was something like this.

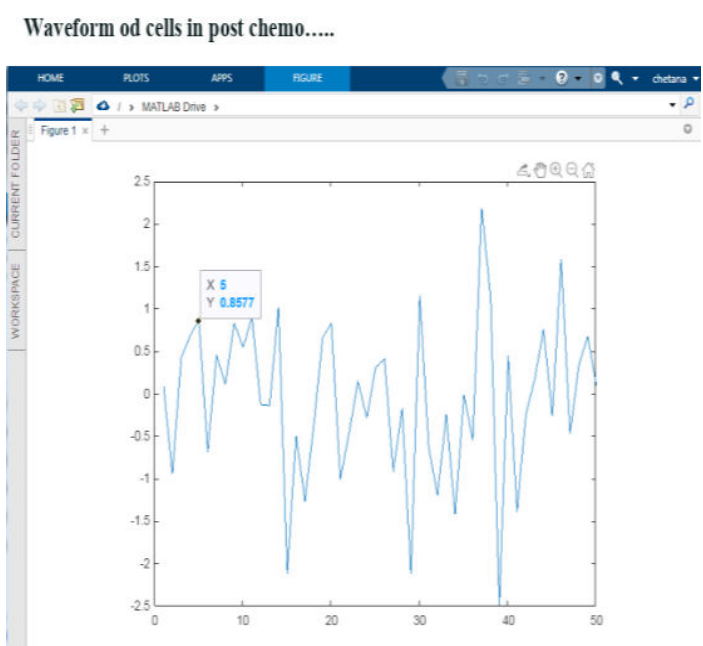

Fig.7: Waveform of cells in chemo

The following table shows the advantages of levitation over chemo.

\begin{tabular}{l|l|}
\hline Chemo & Levitation \\
$\begin{array}{l}\text { Causes post complications } \\
\text { like hairloss }\end{array}$ & Has no harm on the user \\
\hline $\begin{array}{l}\text { The user is prone to get } \\
\text { cancer or stone again due to } \\
\text { trace leaving of cells }\end{array}$ & $\begin{array}{l}\text { Completely destroyes the } \\
\text { cells leaving no traces }\end{array}$ \\
$\begin{array}{l}\text { Suitable only during first } \\
\text { stages of diseases }\end{array}$ & $\begin{array}{l}\text { Can cure disease at any point } \\
\text { of time }\end{array}$ \\
\hline $\begin{array}{l}\text { Uses Radiations which is } \\
\text { again a harm to smooth cells }\end{array}$ & Works in an algorised manner \\
\hline
\end{tabular}

Fig.8: Chemo and Levitation

\section{Conclusion}

This study made a conclusion that the levitation is a better treatment than chemo.

\section{Acknowledgement}

This project is financially and technically aided by SSNCE.

\section{References}

[1] Dr Jyaprada, "Upliftment of cells", IEEE journal, volume 4, issue 3, November 12, page: 23 to 56 .

[2] Dr Asiermargo, "Cell structure", IEEE journal, volume 3, issue 7, November 12, page: 23 to 67. 